\title{
El capital social de la televisión: el movimiento asociativo de telespectadores en España
}

\author{
Gloria RosiQue Cedillo \\ Universidad Carlos III de Madrid \\ grosique@hum.uc3m.es \\ Francisco GARCÍA GARCÍA \\ Universidad Complutense de Madrid \\ fghenche@gmail.com
}

Recibido: $15 / 03 / 2011$

Aceptado: 22/06/2011

\section{Resumen}

Si bien en la actual oferta televisiva en abierto continua primando la falta de creatividad y calidad de los contenidos, esta tendencia parece estar cambiando con la participación de la ciudadanía organizada en "asociaciones de telespectadores", quienes vienen desarrollando prácticas de control sobre el ejercicio de las empresas audiovisuales y los contenidos televisivos, presionando hacia la autorregulación. Estas acciones podrían estar afectando el ejercicio de los distintos agentes televisivos, lo cual propiciaría la revisión de la teoría de los medios y abriría nuevas discusiones sobre los paradigmas con los que se vienen explicando los fenómenos sociales de la comunicación.

Palabras clave: Contenidos de televisión, asociaciones de telespectadores, políticas televisivas, ciudadano-telespectador, televisión digital en abierto, agentes televisivos.

\section{The TV human capital: the associative movement of TV viewers in Spain}

\begin{abstract}
In the present sector of TV contents prevails the lack of creativity and quality. Nevertheless this tendency seems to be changing with the participation of the citizenship organized in "associations of TV viewers". These associations have been developing practices of control to regulate the audio-visual companies and the TV contents, betting by the self-regulation in the audiovisual sector. These actions could be affecting the exercise of the different TV agents, which would cause the revision of the theory of means and would open new discussions on the paradigms with which they come explaining the social phenomena from the communication.

Keywords: TV Contents, TV Viewers associations, TV policies, Citizens television viewers, Broadcasting Digital TV, TV agents.

\section{Referencia normalizada}

ROSIQUE CEDILLO, Gloria y GARCÍA GARCÍA, Francisco (2011): "El capital social de la televisión: el movimiento asociativo de telespectadores en España". Estudios sobre el mensaje periodístico, vol. 17, núm. 2, págs.: 595-614. Madrid, Servicio de Publicaciones de la Universidad Complutense.

Sumario: 1. Introducción. 2. Hacia una definición de la televisión de nuestros tiempos. 2.1. Los nuevos soportes de la comunicación. 3. El contexto legislativo. 3.1. La Ley General de Comunicación Audiovisual. 4. Historia y creación del movimiento asociativo de telespectadores en España. 4.1. Funciones de las Asociaciones de Telespectadores. 4.2. Estructura organizativa. 4.3. Objetivos y actividades de las Asociaciones de Telespectadores. 5. Análisis DAFO de las Asociaciones de Telespectadores. 5.1. Debilidades. 5.1.1. Falta de visibilidad cara a la ciudadanía. 5.1.2. Financiación. 5.1.3. Representatividad. 5.1.4. Falta de participación ciudadana. 5.1.5. Legitimidad. 5.1.6. Profesionalización. 5.2. Amenazas. 5.2.1. Nuevas tecnologías. 5.2.2. Contexto político y social. 5.3. Fortalezas. 5.3.1. Figura mediadora, espacio de mediación. 5.3.2. Organización y trabajo conjunto. 5.4. Oportunidades. 5.4.1. Contexto político, social y legislativo. 6. Conclusiones. 7. Referencias bibliográficas.
\end{abstract}




\section{Introducción}

Tal y como señala QuiRóz (1993, 53), en una primera etapa, la televisión fue estudiada como un medio electrónico que transmitía ideas y contenidos pero no en términos de una comunicación bidireccional, ya que se ignoraba que entre el público y el medio se producían relaciones de intercambio. En las nuevas corrientes, la televisión no se entiende como un proceso único de emisión y de recepción, sino que entre la producción (emisión) y el consumo (recepción), operan una serie de momentos, circunstancias, personas, grupos y lugares que "median" la relación comunicacional".

La línea de investigación que se enfoca particularmente a estudiar la influencia de los telespectadores sobre la televisión resulta muy incipiente, ya que, si bien se ha demostrado que entre el emisor y el receptor se produce el feed back, no se ha determinado en qué medida los telespectadores afectan al medio.

El objetivo principal de este artículo es el estudio de la televisión en referencia a los telespectadores organizados en "Asociaciones de Telespectadores" y a la posible influencia que estos ejercen sobre los contenidos que se emiten en la televisión generalista en abierto y respecto al ejercicio de los tradicionales agentes televisivos: Estado, cadenas de televisión y anunciantes.

\section{Hacia una definición de la televisión de nuestros tiempos}

Hace poco menos de cinco décadas que la televisión entró en los hogares españoles y desde entonces comenzaron a formarse los primeros públicos o telespectadores, con las connotaciones que implícitamente llevarían hasta hace muy poco: telespectadores pasivo-receptores y sin posibilidad real de interacción con el medio. Incrédulos ante la magnificencia de esta nueva tecnología que se convertía en el centro de sus miradas y que poco a poco iría construyendo sus deseos y sus imaginarios sociales, hasta hace muy poco el telespectador ha presentado brotes de una muy lenta transformación hacia el terreno de la participación y la toma de conciencia de su papel como ciudadano-telespectador, siempre supeditada a los deseos del medio televisivo, en comparación con la historia evolutiva de este medio en materia tecnológica²:

"La televisión analógica ha sido, por su propia naturaleza, un medio de comunicación unidireccional, pero las comunicaciones electrónicas abren la posibilidad no sólo a una bidireccionalidad entre emisor (operador) y receptor (espectador), sino a una interacción en red de todos los intervinientes en el proceso comunicativo. Ello estimula el mito de la televisión participativa [...]" (AUC, 2009: web).

Sin embargo, la televisión abarcaría únicamente una primera fase en la historia de lo audiovisual, seguida por una segunda encabezada por la llegada de Internet y el pos-

\footnotetext{
${ }^{1}$ De acuerdo con ABruzZese y Miconi (1999: 209): “examinar la televisión desde el punto de vista de la tecnología o desde el punto de vista del consumo ha constituido tradicionalmente una elección radical, drástica".

${ }^{2}$ A la televisión en blanco y negro le siguió la de color, el mando a distancia, la posibilidad de grabar programas y retrasmitirlos, hasta llegar a tener la posibilidad de confeccionar su propia parrilla de programación y de visionarla en cualquier momento, gracias a la televisión a la carta.
} 
terior desarrollo de la telefonía móvil, hasta conformar el panorama audiovisual actual en el que conviven varios soportes de difusión de información e imágenes basados en la convergencia con las nuevas tecnologías de la información y la comunicación (TIC).

La tendencia que hasta ahora han venido siguiendo los medios de comunicación ha sido la de converger y adaptarse unos a otros, aprovechando las posibilidades que cada uno le brinda, creando así nuevas formas de expresión y de comunicación en las que los telespectadores se han convertido en usuarios polivalentes de estos nuevos medios y en actores protagonistas de su desarrollo.

\subsection{Los nuevos soportes de comunicación}

Los avances tecnológicos han llevado a la televisión analógica en España al terreno digital (TDT) con los cambios que con ello ha conllevado: multiplicidad de canales, mayor calidad en la imagen, mayores posibilidades interactivas para el usuario y el aumento de la oferta televisiva ${ }^{3}$, pese a que, tal como lo evidencia la Asociación de Usuarios de la Comunicación (AUC) en su último análisis de evolución de la audiencia en televisión:

“ [...] dos tercios del consumo televisivo terrestre sigue concentrándose en las mismas ofertas que los espectadores podían ver antes del apagón analógico. Cabe pensar hasta que punto ello puede estar condicionado por la falta de atractivo de la nueva programación digital (con excepción de los canales temáticos infantiles) y el poco esfuerzo de los operadores en ese sentido" (AUC, 2010: web).

La irrupción de Internet ${ }^{4}$ ha modificado el negocio de la televisión a través de la apertura de nuevas vías de desarrollo, pero también ha influido en los hábitos y en los usos que hasta entonces los telespectadores venían haciendo de este medio de comunicación. Hoy en día es inconcebible pensar que una empresa audiovisual no cuente con su propio portal de Internet, esta nueva ventana conectada al mundo que le ha permitido expandir su negocio y acercarse a un telespectador prácticamente desconocido hasta entonces, que durante décadas quedó limitado a una representación numérica a través de los índices de audiencia. Fue una época incipiente para los telespectadores en la que las cadenas generalistas de televisión se escudaban en los índices de audiencia para legitimar su discurso acerca de la programación que emitían, aludiendo que eran los gustos del público los que determinaban la confección de sus parrillas de programación.

Esa denominada "audiencia" de antaño, actualmente cada vez más fragmentada dada la multiplicidad de canales y de oferta audiovisual, hoy en día tiene otras formas

${ }^{3}$ En este sentido cabría hacer una reflexión en torno a la existencia de una mayor oferta de contenidos, ya que las principales cadenas generalistas españolas como en el caso de "Telecinco", han optado por emitir los mismos contenidos de su canal principal a su nuevo canal (Siete), sin variar en absoluto su programación, ni brindarle al telespectador nuevas propuestas en materia de contenidos.

${ }^{4}$ En referencia a Internet, GARCÍA y GERTRÚDIX (2009) lo describen como un espacio en el que conviven la libertad y el control, la desregulación y el derecho, la ilusión de la frontera libre y el anhelo del hombre sujeto a la Ley, ese es el "Mare Nostrum Digital". 
de interactuar con los medios de comunicación gracias a las redes sociales, al auge del periodismo participativo o ciudadano y a la proliferación de medios alternativos más cercanos a públicos e intereses "locales", que van dentro de la tendencia a la especialización de los contenidos y de la, hasta a veces contradictoria, convivencia entre lo local y lo global ${ }^{5}$.

Asimismo, Internet le ha abierto la posibilidad a este nuevo usuario de los medios de comunicación de ser protagonista en la creación y difusión de sus propios contenidos audiovisuales ${ }^{6}$, son, en definitiva, prosumidores (TOFFLER, 1988), productores y consumidores a la vez; estas nuevas formas de interacción han dejando al descubierto las verdaderas preferencias ${ }^{7}$ de los usuarios de los medios rompiéndose así la tradicional concepción del telespectador pasivo-receptivo.

Llegados a este punto, es una realidad que actualmente los medios de comunicación han perdido el status de únicos portadores de la información y constructores de la realidad, ante el auge de un nuevo usuario de los medios, capaz de emitir sus propios contenidos e imágenes a través del ciberespacio y hacerlos circular por la inmensidad de la red, portando al mismo tiempo sus opiniones y visiones del mundo. Resulta evidente que en la actualidad "los ciudadanos tienen cada vez más plataformas donde ver y producir vídeos y programas alternativos a la televisión convencional"8 (VARELA, 2006: web).

En este sentido hoy cobra especial importancia la célebre frase que acuñó Francis Bacon, "Scientia potentia est" (información es poder), ya que con estas nuevas prácticas comunicativas a través de la llamada Web 2.0, los nuevos soportes y la facilidad de distribución de información e imágenes que actualmente tiene al alcance cualquier usuario mínimamente alfabetizado a nivel tecnológico, pareciera que los medios de comunicación tradicionales estuvieran perdiendo fuerza como únicos emisores y constructores de la realidad. Sin lugar a duda, "ahora la tendencia más innovadora es la de trasladar el universo de los cibermedios de las redes fijas a las redes de comunicación de movilidad propiciadas por la telefonía móvil. Las comunicaciones móviles expe-

5 "Las tecnologías de última generación, que van desde Internet al Weblog pasando por la televisión y la radio digital interactiva, no sólo globalizan el mercado y los flujos económicos, no sólo coadyuvan a la homogeneización del pensamiento. También globalizan contenidos culturales minoritarios, posibilitan el desarrollo de iniciativas de carácter colectivo, abren posibilidades de generar información al margen de las grandes corporaciones de la comunicación. Es decir: incorporan pluralismo, diversidad, educación" (CAFFAREL, 2007: 5).

${ }^{6}$ Youtube fue el primero que abrió la vereda a esta tendencia.

${ }^{7}$ El último fenómeno en Internet es el "Lipdub". Son vídeos musicales caseros realizados en una sola toma o plano secuencia, en la que los participantes hacen play back de sus canciones favoritas, aportando su propia apuesta en escena.

8 "Pluralia TV es una de ellas, una televisión valenciana que desde 2003 intenta crear una televisión con la que todos podamos crecer culturalmente, con la que todos podamos aprender y enseñar; una televisión desde la cual luchar por nuestros derechos... una televisión que no sea ese potaje de telebasura, famoseo y manipulación política que son las televisiones actuales" (VARELA, 2006: web). 
rimentan otros espacios y tiempos, otras formas expresivas, otros consumos y otras formas de comunicación" (CEBRIÁN, 2009: 10).

En definitiva, estas nuevas formas de comunicación han roto el paradigma del esquema de comunicación unidireccional que, hasta la entrada de Internet, detentaban los medios tradicionales de comunicación (radio, prensa y televisión), abriendo paso a una nueva filosofía en la que prima la distribución de la información desde varios emisores hacia varios receptores ${ }^{9}$.

\section{El contexto legislativo}

Desde sus comienzos, la regulación de lo televisual ha sido objeto constante de control e intervención por parte del poder estatal. Un poder centralizado que gestionó la televisión en régimen de monopolio "bajo el carácter de servicio público con el que inició la televisión en Europa" (FuENTE CoBO, 1989: 23).

A raíz de la concesión de licencias privadas de televisión ${ }^{10}$ que dio fin al monopolio de la televisión pública a finales de la década de los 80 , este medio de comunicación comenzó su regulación a través de la primera legislación española en materia audiovisual, el Estatuto de la Radio y la Televisión ${ }^{11}$. Desde entonces se han puesto en marcha diversos códigos deontológicos y de autorregulación ${ }^{12}$ como lo fue el "Convenio para la autorregulación de la emisión de contenidos violentos, discriminatorios y sexistas" (1993) y uno de más reciente creación, el "Código de Autorregulación de los Contenidos Televisivos e Infancia" (2004), todos ellos destinados a que las empresas de televisión cumplieran con su función de portadoras de un servicio público desde una gestión privada y se apegaran a la normativa audiovisual vigente.

A lo largo de todos estos años de legislación en esta materia se ha puesto especial énfasis en la protección del público infantil, se ha implementado una señalización especial para los programas con el objetivo de brindarle mayor información al telespectador sobre la idoneidad del contenido de los programas, se ha hecho hincapié en la programación que emiten las cadenas poniendo especial atención en los contenidos de baja calidad ${ }^{13}$, etcétera. Asimismo, han surgido diversas iniciativas civiles por parte

9 "Los blogs están dando voz y presencia pública a la gente corriente que tienen cosas que decir, que no necesariamente saben acerca de tecnología, de diseño, o de programación (...) la blogosfera como red se ha convertido en el quinto poder, un poder que controla al poder político y al poder mediático" (ARrIBAS, 2010).

${ }^{10}$ Ley 10/1988, de 3 de mayo, de Televisión Privada.

${ }^{11}$ Ley 4/1980, de 10 de enero, de Estatuto de la Radio y Televisión.

${ }^{12}$ Como ejemplo, el 19 de septiembre de 2000, el Parlamento Europeo declaró lo siguiente: «es urgente que todos los operadores televisivos europeos establezcan un código de autorregulación en materia de protección de menores que contenga mecanismos de control social y cláusulas severas de sanción en caso de incumplimiento» (Código de Autorregulación sobre contenidos televisivos e infancia).

${ }^{13}$ El Senado implementó una "Comisión Especial sobre los contenidos televisivos" que trabajó entre los años 1993-1995, misma que propuso desde entonces la creación de un Consejo Audiovisual. 
de diversas asociaciones y observatorios de los medios para intentar regular un sector en constante crecimiento, que hoy en día no sólo abarca el espectro televisivo, sino el universo de la red de Internet y su convergencia con este medio ${ }^{14}$.

A pesar de la existencia de las asociaciones de telespectadores y a la labor que vienen realizando desde su creación ${ }^{15}$, estudios sobre los contenidos audiovisuales que se emiten en las cadenas generalistas en España, las tareas que llevan a cabo como precursores de la "alfabetización audiovisual" en los telespectadores, su participación frente al resto de agentes sociales: cadenas de televisión, anunciantes y el Estado, actualmente su función continua siendo prácticamente imperceptible por la ciudadanía. Pese a los esfuerzos por mantener un orden en el sector audiovisual y brindarle un mejor servicio a la ciudadanía, actualmente la complejidad del nuevo marco audiovisual y su regulación, sin lugar a dudas sigue siendo uno de los mayores retos para la administración pública española y para las autoridades europeas, ya que la tecnología y la comunicación avanzan a pasos agigantados en contraposición a una legislación que pareciera estar desfasada de las necesidades reales de todos aquellos usuarios de la comunicación.

\subsection{La Ley General de la Comunicación Audiovisual}

En el artículo sexto sobre el "derecho a una comunicación audiovisual transparente" de la reciente Ley General de la Comunicación Audiovisual ${ }^{16}$ en su cuarto apartado hace referencia, por primera vez en España, a que los poderes públicos y los prestadores del servicio de comunicación audiovisual deben "contribuir a la alfabetización mediática de los ciudadanos", cuestión de la que hasta ahora se venía ocupado las asociaciones de telespectadores llevando a cabo diversas tareas a este respecto; sin embargo, cabe señalar que no han tenido apoyo para la difusión de estas actividades cara a la ciudadanía, tan necesarias en estos tiempos. De este modo, tal y como lo señala PÉrEZ TorNERO (2010: web), "la competencia mediática de los ciudadanos deja de ser un asunto estrictamente privado (personal y familiar) para convertirse en materia esencial de la esfera pública". También, en la Ley General de la Comunicación Audiovisual, en su artículo séptimo sobre los derechos del menor, cabe destacar la promoción, entre los prestadores del servicio de comunicación audiovisual televisiva de "códigos de conducta" en relación con la comunicación comercial audiovisual inadecuada.

Cabe hacer mención, llegados a este punto, de la infinidad de iniciativas adoptadas a este respecto que hasta el día de hoy no han significado un verdadero cambio en

${ }^{14}$ Tal es el caso de la Asociación de Usuarios de la Comunicación (AUC) y de la extensa red de asociaciones de telespectadores repartidas a lo largo de todo el territorio español, representadas a través de la Federación de Asociaciones de Consumidores y Usuarios de los Medios (ICMedia).

${ }^{15}$ El renacer de las asociaciones de telespectadores coincide con la entrada de las televisiones privadas en España en la década de los años 80, momento en el que despega la televisión comercial y con ella desajustes e inconformidades, cara a un medio que comenzaba a mostrar indicios de irregularidades en toro a lo normativo y a su programación (ROSIQUE, 2007).

${ }^{16}$ Ley 7/2010, de 31 de marzo, General de la Comunicación Audiovisual. 
materia de regulación. Asimismo, si bien en su artículo noveno sobre "el derecho a la participación en el control de los contenidos audiovisuales" le otorga competencias sancionadoras al Consejo Audiovisual Estatal, se deja entrever una cierta flexibilidad a favor de las empresas audiovisuales. Si bien cualquier persona física o jurídica puede solicitar a la autoridad audiovisual competente el control de la adecuación de los contenidos audiovisuales con el ordenamiento vigente o los códigos de autorregulación, únicamente si la autoridad lo considera oportuno, dictará recomendaciones para un mejor cumplimiento de la normativa vigente.

Por otra parte, dentro de la estructura del Consejo Estatal de Medios Audiovisuales se considera la creación de un Comité Consultivo como "órgano de participación ciudadana y de asesoramiento", en el que se plantea la posibilidad de que las asociaciones de defensa de los usuarios participen, siempre y cuando cumplan el requisito de "representatividad" en cuanto a número de usuarios afiliados.

\section{Historia y creación del movimiento asociativo de telespectadores en España}

El inicio del movimiento asociativo de telespectadores en España se remonta a los años 80's (Rosique, 2007), década en la que data la inscripción en el Registro Nacional de Asociaciones en el Ministerio del Interior la primera Asociación Española de Espectadores de Televisión (1980) y que coincide con la elaboración del Estatuto de la Radio y la Televisión (Ley 4/1980, de 10 de enero). Este hecho no es producto de la casualidad, ya que las asociaciones de telespectadores comienzan a organizarse debido a que en esta ley, y por primera vez en la historia de la televisión en España, se hace mención de las asociaciones de telespectadores como posibles colaboradoras de los "Consejos Asesores".

A este respecto cabe destacar que a día de hoy se les ha presentado una segunda oportunidad desde entonces, para formar parte del Comité Consultivo del CEMA, como se ha mencionado anteriormente. Esto se estipula así con el objetivo expreso de que la sociedad civil tuviera representación y fuera partícipe en la toma de decisiones, en un contexto en el que se estaba diseñando la ley para la Radiotelevisión Española (RTVE) y donde el término de "servicio público" salía a flote.

A pesar de que Televisión Española (TVE) llevaba ya varios años emitiendo, los contenidos televisivos se mantenían muy al margen de cualquier tipo de polémica, lo que no suscitó el interés inmediato de la sociedad civil por hacerse partícipe. Quizás por ello tampoco resultó prioritaria su función, en un panorama audiovisual que comenzaba a construirse y donde la televisión y la ciudadanía aún no sabían de diferencias.

El renacer de las asociaciones de telespectadores se hace presente justamente con la entrada de las televisiones privadas, momento en el que despega la televisión comercial en España y con ella, desajustes e inconformidades cara a un medio que comenzaba a mostrar indicios de irregularidades en torno a lo normativo y a la programación, además de disparidades entre lo que algunos sectores de la sociedad española esperaba de su televisión. En este segundo periodo, que podría identificarse con el verdadero comienzo del movimiento asociativo de telespectadores, comienzan a crearse la mayor parte de las asociaciones existentes al día de hoy tales como la (AUC) "Asociación de Usuarios de la Comunicación" (1983) que actualmente se constituye 
como una de las más importantes en España, junto con la (ATR) “Agrupación de Telespectadores y Radioyentes" (1985), que tiene representación en gran parte del territorio español, así como (iCmedia) la "Federación de Asociaciones de Consumidores y Usuarios de los Medios" creada con el nombre de FIATYR en 1992, la cual agrupa a la mayor parte de asociaciones de telespectadores incluida a una que opera en ámbito portugués y el "Foro del Espectador" (2001).

En ese contexto, y debido a las continuas faltas en las que incurrían las empresas audiovisuales, había un descontento generalizado de estos grupos frente a una televisión que operaba muy flexible en materia de contenidos, al tiempo que percibían una sobreexplotación comercial y una regulación muy laxa por parte del gobierno. A continuación se muestran algunas de las iniciativas gubernamentales más destacadas en el ámbito de la regulación televisiva implementadas desde entonces para llevar a cabo esta labor y que hasta ahora no han tenido el éxito esperado en esta materia:

- Convenio para la autorregulación de la emisión de contenidos violentos, discriminatorios y sexistas' (Marzo 1993)

- Comisión Especial sobre contenidos televisivos' (Senado, 1993-1995)

Sistema uniforme de señalización de los programas de TV en función de su grado de idoneidad para los menores' (Octubre 1999)

- Consejo para la Reforma de Medios de Comunicación de Titularidad del Estado (2001)

- Convenio de Autorregulación de la publicidad (2002-2003)

- Código de Autorregulación sobre contenidos televisivos e infancia (Dic.2004)

Desde entonces las inconformidades presentes entorno a la televisión que se estaba generando en esos momentos se fueron canalizando a través de la movilización de estos grupos de telespectadores y de organizaciones de todas las comunidades del país, que al día de hoy y de manera generalizada, a pesar de las diferencias existentes entre ellas, siguen apostando por una televisión alternativa, creativa, con apego a ciertos valores y respetuosa con la normativa vigente que regula el sector audiovisual.

\subsection{Función de las asociaciones de telespectadores}

En palabras de José Boza Osuna (2005: 114-115), las asociaciones de telespectadores (ATR's) son "grupos de asociados que consumimos los medios y que juntos, queremos contribuir a su mejor uso, distribución y producción". Su función principal y más destacada es la de colaborar desde la sociedad civil a la construcción de la ciudadanía audiovisual, poniendo énfasis no únicamente en la "calidad del producto", sino en la "calidad del acto de consumo".

Asimismo, promueven la concienciación de los mensajes y usos televisivos, a través de la alfabetización audiovisual o educomunicación, entendida como una herramienta que "aspira a dotar a toda persona de las competencias expresivas imprescindibles para su normal desenvolvimiento comunicativo y para el desarrollo de su creatividad" (GARCíA MATILLA, 2006: web), y que resulta indispensable poner al alcance del telespectador que convive y hace uso de los diferentes medios de manera cotidiana, además de vislumbrarse como una vía para despertar la capacidad crítica de los telespectadores. 
El conjunto de asociaciones de telespectadores vienen desempeñando la tradicional función de "canalización de demandas" mediante la presión, a la vez que se une la función de "representación o intermediación" de intereses mediante la presencia en espacios y órganos a través de los cuales participan en las decisiones relativas a la formación y aplicación de políticas públicas (NAVARRO y JUARISTI, 2006), como es el caso concreto de la Asociación de Usuarios de la Comunicación (AUC).

\subsection{Estructura organizativa}

En el panorama asociativo de telespectadores en España cohabitan tres grandes asociaciones independientes y una federación., la "Federación de Asociaciones de Consumidores y Usuarios de los Medios" (ICMedia), la cual está conformada por 17 asociaciones de telespectadores que se encuentran repartidas en las distintas provincias españolas, con excepción de AC media Portugal que como su nombre lo indica tiene su sede en Portugal.

Entre las asociaciones que persiguen objetivos similares cabe destacar la Asociación de Usuarios de la Comunicación (AUC), las Asociaciones de Telespectadores y Radioyentes (ATR' s) y el Foro del Espectador. Estas tres asociaciones se desarrollan en el ámbito audiovisual español haciéndose presentes a través de las campañas y actividades que realizan en los medios de comunicación, y quienes se autodefinen como "mediadoras" dentro de la cadena de valor del sector audiovisual, actuando como punto de enlace entre la ciudadanía y los agentes televisivos: Estado y anunciantes.

\subsection{Objetivos y actividades de las asociaciones de telespectadores}

Las asociaciones de telespectadores nacen para convertirse en el canal a través del cual lleguen las opiniones y sugerencias de la audiencia a las cadenas de televisión y radio y, para que de este modo se fomenten espacios de calidad y buen gusto en cualquiera de sus facetas: información, formación y entretenimiento (ATR, 2010: web). Asimismo, uno de sus principales fines es el de vigilar para que se aplique lo estipulado tanto en la normativa europea sobre Televisión sin Fronteras, como en el cumplimiento, principalmente por parte de las empresas audiovisuales, de los códigos y normativas hasta ahora implementados en esta materia. Entre sus objetivos generales figuran los siguientes:

- Proteger a la infancia y a la juventud de los abusos de los medios, efectuando las oportunas reclamaciones ante las autoridades del Estado y los directivos de las distintas cadenas.

- Velar por el cumplimiento escrupuloso de las leyes vigentes, de los convenios deontológicos y códigos de autorregulación asumidos por los medios de comunicación social.

- Crear en las familias una conciencia crítica que desarrolle su capacidad de elección y juicio, ante la amplia gama de ofertas televisivas y radiofónicas existentes.

- La consecución de una televisión de calidad, respetuosa con los derechos y valores de la audiencia (objetivo principal de las ATR's).

- La defensa de los derechos de los usuarios, especialmente de los menores. 
Actividades que llevan a cabo:

- Seguimiento de los contenidos de TV (Observatorio de los medios).

- Informes.

- Propuestas, reclamaciones y comunicados a las cadenas de televisión.

- Acuerdos gubernamentales de cooperación.

- Concesión de premios anuales (a los programas de TV y mejores profesionales).

- Cursos, campañas, seminarios sobre educación para los medios.

- Publicación de un Boletín informativo.

Cabe destacar que entre las asociaciones de telespectadores hay algunas diferencias sustanciales, así como independencia en cuanto a las actividades que realizan, aunque todas persiguen de manera general los objetivos anteriormente mencionados. Asimismo, las asociaciones de telespectadores tienen representación a nivel internacional a través de European Associations for Viewers Interests (EAVI) y de la Alianza Europea de Oyentes y Asociaciones de Telespectadores (EURALVA), de la cual forma parte iCmedia.

\section{Análisis DAFO de las Asociaciones de Telespectadores \\ 5.1. Debilidades}

\subsubsection{Falta de visibilidad cara a la ciudadanía}

Las estrategias de comunicación que hasta el día de hoy vienen siguiendo estas asociaciones, si bien han estado encaminadas a acercarse a su público objetivo, padres de familia y jóvenes en el caso de las ATR' s y el Foro del Espectador y a un público joven y adulto en el caso de la AUC, a través de las actividades que desarrollan parecieran no estar dando los frutos deseados ya que se detecta un desconocimiento por parte de la ciudadanía en relación a estos grupos. Esto lleva a pensar en la necesidad acuciante por parte de estas asociaciones de diseñar nuevas estrategias de comunicación que les permitan hacerse visibles y hacer llegar su mensaje a un mayor número de telespectadores para dar a conocer sus objetivos y actividades con mayor eficacia a la ciudadanía, partiendo de la hipótesis de que el número de asociados que respalda este movimiento es vital para la consecución de sus fines y para logar su "representatividad" en los órganos de gobierno.

Es probable que la falta de confianza hacia ellas tenga sus raíces en la misma desinformación o en la falta de información que tiene la ciudadanía sobre estas organizaciones, siendo la confianza "un componente esencial del capital social, ya que la confianza lubrica la cooperación" (FERNÁNDEZ SANTILlÁN, 2005).

"La primera gran dificultad que debe afrontar el asociacionismo audiovisual es que mientras en otros colectivos de consumidores está perfectamente claro el objeto de consumo y el marco en el que se desarrolla su actividad, en nuestro caso, no sólo debemos luchar de inicio con la intangibilidad del objeto de consumo -el complejísimo producto audiovisual- y con la extraordinaria complejidad del mercado, sino que, además y sobre todo, debemos afrontar la inconsciencia de los consumidores a los que representamos respecto de su propia condición de tales, teniendo que hacer una dura tarea previa a cualquier otra iniciativa para convencerles de que realmente lo son" (Boza Osuna, 2005: 113). 


\subsubsection{Financiación}

Otra de las debilidades encontradas en las asociaciones de esta índole es la falta de medios económicos para llevar a cabo sus proyectos. Esto se traduce en limitaciones para su ejercicio, ya que cuentan con un presupuesto muy bajo que logran recabar gracias a las cuotas de sus asociados y, en algunos casos como es el de la Asociación de Usuarios de la Comunicación (AUC), con investigaciones que lleva a cabo para diversas empresas. Cabe hacer mención de que algunas de ellas a lo largo de su historia, han recibido algunos apoyos gubernamentales puntuales. En este sentido, sería importante que estos grupos pudieran incorporarse a fuentes de financiación pública e institucional, tal como asiente el Presidente de la Asociación de Telespectadores y Radioyentes de Aragón en Zaragoza, José BozA Osuna (2005: 114).

\subsubsection{Representatividad}

Uno de los puntos clave a destacar dentro de este apartado es la "representatividad", entendida como el problema que tienen estos grupos de vivir en la siguiente dualidad:

a) Ser concebidos como asociaciones que hablan en representación del conjunto de "ciudadanos telespectadores"

b) Ser percibidos como asociaciones o agrupaciones que representan a un grupo identificado de personas o socios que comparten una ideología común, referente a la situación de los contenidos y a la televisión en abierto.

Es necesario aclarar que estas organizaciones, si bien han nacido desde la sociedad civil, sólo representan a un grupo específico conformado por todos aquellos afiliados a estas agrupaciones o quienes, sin ser socios necesariamente, comparten sus puntos de vista participando a través de llamadas telefónicas, enviando correos electrónicos o pronunciándose respecto a determinadas emisiones.

Si bien al día de hoy todos ellos conforman un grupo numeroso de asociados, como resultado de la sumatoria de los asociados de todas y cada una de las asociaciones de telespectadores, aún se tienen dudas acerca de si realmente pueden llegar o no a ser considerados como "grupos representativos" de la ciudadanía para formar parte del Consejo Consultivo del Consejo Estatal de Medios Audiovisuales.

Las asociaciones de telespectadores son conscientes de ello, ya que uno de los principios básicos de cualquier asociación es que entre sus miembros compartan los mismos fines, por lo que no pretenden ser una vox populi, pero sí ser escuchados como tantas asociaciones existentes que luchan, por las causas que consideran relevantes. Desde sus orígenes dichas organizaciones civiles buscan tener representación en los órganos de gobierno para ser escuchados, sin embargo son grupos que tienen determinados puntos de vista sobre la televisión que no son compartidos por toda la sociedad, una sociedad plural, heterogénea y diversificada, cuestión que debilita su discurso y sus acciones cara al Estado para que sean tomadas en cuenta en la toma de decisiones en torno a lo televisual.

El discurso gubernamental se ciñe a considerar que estos grupos están conformados mayoritariamente por padres de familia, respaldados por el sector educativo, organizaciones familiares, militantes de los derechos del hombre, grupos católicos, entre otros, quienes encabezan el movimiento asociativo de telespectadores. 
Es posible cuestionarse si los ciudadanos telespectadores se sienten o no identificados con los objetivos de las asociaciones hasta ahora presentes en el panorama televisivo y, por consiguiente, si decidirían o no apoyarlas en la consecución de este movimiento. De obtener una respuesta afirmativa, habría que fortalecer las estrategias de comunicación que al día de hoy, utlizan las asociaciones para darse a conocer cara a la sociedad civil, empero, y como en toda sociedad existe la pluralidad de opiniones. Considerando una negativa a la pregunta planteada, la sociedad civil debería comenzar a crear más asociaciones, lo que daría como resultado la incompatibilidad en los puntos de vista entre ellas, provocando un disgregamiento que quizá pondría a los gestores de televisión, a los anunciantes y a los representantes del Estado, en una situación favorecedora para que las asociaciones de telespectadores no consolidaran su participación en los órganos de gobierno debido a la falta de cohesión; sin embargo, sería un punto positivo, ya que estaríamos hablando del despertar de la sociedad civil en este sector.

\subsubsection{Falta de participación ciudadana}

El problema radica en sí en la percepción que puede tener la sociedad u opinión pública sobre las asociaciones de telespectadores ya que, en el primer caso, puede provocar confusiones que lleve a la ciudadanía al terreno de la desconfianza al verse representados por una asociación de la que tienen escasa o nula información, lo que podría conducirles al rechazo y, por consiguiente, se estaría hablando de una de las posibles causas de la falta de participación ciudadana en estas organizaciones. "Es necesario aumentar el nivel de confianza entre los consumidores para generar en éstos un papel más activo de cara a las innovaciones razonables de oferta y de cara también a conseguir un mayor grado de participación de la sociedad civil organizada" (AUC, 2010: web).

Una vez más, lo trascendente sería que se tomara conciencia de la importancia de la participación ciudadana como "capital social" en los asuntos que le atañen a la sociedad en su conjunto.

\subsubsection{Legitimidad}

La "legitimidad" de las asociaciones tendría que ser evaluada por la propia sociedad civil y su mayor arma sería su comunicación externa para la construcción de su imagen pública, donde la información que den a conocer es pieza clave para que estas agrupaciones puedan llegar a alcanzar niveles de aceptación mayores de en sociedad civil, pudiendo así quizás, lograr su consolidación como 'grupos de presión' valiosos en la sociedad mediática. En este sentido, cabe señalar que la participación en las organizaciones que conforman la sociedad civil es la escuela básica de la democracia, donde la fuerza del asociacionismo es un elemento esencial para el desarrollo político y económico (TOQueville en FERNÁNDEZ SANTILlán, 2005: 56-58).

Otro aspecto interesante a considerar es que estos grupos organizados no deben priorizar a los contenidos televisivos sobre los ciudadanos-telespectadores, es decir, el énfasis de hacer una 'televisión alternativa' no debe tener su origen en los contenidos mismos, sino en llevar a la acción a las audiencias, verdaderas promotoras del cambio (Orozco, 1996: 145-147). 
Otra cuestión que podría enmarcarse dentro de este apartado y que supone una amenaza para ciertas asociaciones de telespectadores, son los cambios tecnológicos inherentes al sector audiovisual. Las nuevas tecnologías obligan prácticamente a estos grupos a abrir sus cauces y a no limitar su ejercicio a la radio y a la televisión analógica. Un ejemplo de ello es la "Asociación de Usuarios de la Comunicación” (AUC) que denuncia, asimismo, abusos referentes a la telefonía móvil, en contraposición con el 'Foro del Espectador' y las Asociaciones de Telespectadores y Radioyentes' que se ciñen, hasta estos momentos, a los medios de comunicación tradicionales.

\subsubsection{Profesionalización}

Más que una falta de organización de estas asociaciones, ya que cabe recordar que se encuentran agrupadas en diferentes órganos tanto a nivel nacional (iCMedia) como internacional (EURALVA), cabría destacar su falta de profesionalización. Si bien, algunas de ellas como la Asociación de Usuarios de la Comunicación (AUC) y la Agrupación de Telespectadores y Radioyentes (ATR), poseen una estructura y un funcionamiento mucho más cercano a la profesionalización de sus tareas, las asociaciones restantes aún están en vías de dar a conocer sus objetivos y servicios como mediadores entre la ciudadanía y medios de comunicación que promueven.

Sin lugar a dudas es importante destacar la iniciativa ciudadana en su ejercicio y el empeño por crear asociaciones de telespectadores. La mayoría de ellas se limita a la iniciativa de algunos ciudadanos de promover cambios en el ámbito mediático, aunado al desconocimiento de cómo actuar y desarrollar sus funciones para darse a conocer.

\subsection{Amenazas}

\subsubsection{Nuevas tecnologías}

Primeramente, las asociaciones de telespectadores deben estar preparadas para afrontar los cambios tecnológicos a los que se está enfrentando el sector audiovisual. Estos grupos tendrán que ir evolucionando a la par de las complejidades del sector para que sus funciones y objetivos sean acordes con las necesidades, y sus tareas y acciones tengan vigencia y utilidad para la ciudadanía.

Es necesario enfatizar que estas asociaciones cumplen una función social, por lo que deben prestar un servicio que sea valorado por la comunidad. El cambio digital en la televisión ha traído consigo un paulatino cambio a nivel de uso de este medio por parte de los telespectadores, ya que hoy en día tiene a su alcance una mayor oferta de canales, aunque esto no se ha traducido en una mayor oferta de contenidos. El que algunas las asociaciones limiten su campo de acción en la línea de promover la defensa de los derechos de los telespectadores en la televisión y en la radio, podría dejarlos, en un momento dado, fuera de contexto. En este sentido resulta necesario que abran su espectro de acción, tal y como lo hace actualmente la Asociación de Usuarios de la Comunicación (AUC), al ámbito de Internet y la telefonía móvil (DE CAMPOS AmAnN, 2005: Entrevista).

Es importante que los ciudadanos vean en estos grupos una utilidad real, acorde con los tiempos en que vivimos y las nuevas necesidades que van apareciendo, en relación a las tecnologías que cada vez van siendo de mayor uso. Ahí es donde la representa- 
tividad es clave para que las asociaciones puedan reclamar frente al Estado, un estatus de utilidad pública y desde esta instancia se les provea de los recursos legítimamente necesarios para mantenerse activos.

\subsubsection{Contexto político y social}

A falta de solidez institucional frente a los órganos del Estado y de una representatividad frente a la sociedad civil no resuelta, la alternancia política constituye una amenaza, toda vez que los cambios de gobierno significan también cambios en la ideología con que se mira a unos u otros grupos de telespectadores organizados, y sobre su participación en los órganos oficiales que gobiernan la televisión española. Específicamente la entrada del gobierno socialista en 2004, dio paso a la idea de participación de algunos de estos grupos en los órganos de gobierno, por lo que su situación ha mejorado. Cabe recordar que durante años anteriores, cuando estos grupos emergieron se les mantuvo al margen de las políticas televisivas, teniendo una actividad muy discrecional respecto a ellas. Hoy en día con la Ley General del Audiovisual se está a la espera de que su participación en un órgano de gobierno se consolide.

\subsection{Fortalezas}

\subsubsection{Figura mediadora, espacio de mediación}

La importancia de las asociaciones de telespectadores radica en sí en la figura que representan. Su función como intermediarios o mediadores dentro de la estructura de poder del sector audiovisual es su mayor virtud, ya que el poder que detenta el Estado, las empresas audiovisuales y los anunciantes, ha desvelado, desde los orígenes de la televisión, un discurso unidireccional en donde el ciudadano telespectador no ha tenido vía alguna para escalar esta pirámide y ser escuchado, quedando siempre relegado a una posición de grupo dominado dentro del campo de lucha mediático, en donde los anunciantes, los propietarios de las cadenas y los políticos del Estado, son los que hacen las reglas que dominan el juego, con mínimas posibilidades de influencia hasta ahora de la contraparte (BOURDIEU, 1974).

El hecho de que estas asociaciones luchen por tener un espacio en el que participen y expongan sus puntos de vista, resulta clave en una sociedad que valora el juego democrático. El pensar en la existencia de las asociaciones de telespectadores lleva también a deducir que algunos grupos se encuentran sensibilizados, conscientes y dispuestos a ejercer sus derechos como ciudadanos usuarios de la televisión y del uso que se debe hacer de ella.

Asimismo y a través de la puesta en práctica de sus acciones, intentan que la fuerza y las decisiones no provengan únicamente de los empresarios, de los anunciantes o del Estado (que desde la política tiene sus propios mecanismos de representatividad debidamente legitimados), sino que, en el intento por encontrar un equilibrio o una relación más justa en las relaciones de poder, la sociedad civil actúe como contrapeso en la balanza del juego audiovisual. Las asociaciones de telespectadores van haciéndose un lugar dentro del sector en materia de contenidos televisivos. Poco a poco estos grupos han ido abriéndose paso y se comienzan a vislumbrar frutos de sus actividades sobre todo en los últimos años, que las van conformando, asimismo, en "grupos 
de presión" que, si bien al día de hoy juegan algún papel en los órganos de gobierno, (pese a que se está a la espera de conocer la conformación definitiva del "Consejo Audiovisual" lo que se traduce en un posible espacio de expresión), tienen un peso ya perceptible en la toma de decisiones en relación a los agentes de la comunicación.

Lo anterior podría traducirse en que, trabajando en coherencia con sus objetivos, podrían lograr posicionarse de un lugar importante para el ejercicio y el futuro desarrollo de sus líneas de actuación, en pro de la defensa de los usuarios de la televisión.Pese a las mínimas diferencias entre las asociaciones de telespectadores que radican básicamente en sus orígenes fundacionales, todas ellas persiguen, en líneas generales, los mismos fines: el de proteger a los usuarios de los medios de comunicación, informarles acerca de sus derechos como ciudadanos y proporcionarles las herramientas necesarias para concienciarse del uso que le dan a la televisión, intentando colocarlos, por primera vez, en una posición menos desventajosa, rompiendo así los cánones establecidos de la cadena de valor enraizados en el tiempo, donde prevaleció la idea de los medios de comunicación como fuerzas únicas e inquebrantables.

Cabe destacar y valorar el recorrido ininterrumpido trazado por estas asociaciones desde la década de los 80 y su empeño por dar a conocer su opinión en relación con lo audiovisual, ya que se están produciendo cambios que pueden ser el preludio de una televisión diferente. En este camino, la sociedad civil tiene dos alternativas: apoyarlas y, por consiguiente, ayudar a la consolidación de las acciones llevadas hasta el momento o, por el contrario, oponerse a sus intervenciones y crecimiento, lo que significaría el estancamiento del movimiento asociativo de telespectadores.

\subsubsection{Organización y trabajo conjunto}

Un punto destacable dentro de este apartado es el trabajo en conjunto que llevan a cabo estos grupos. Destaca el importante papel que están desempeñando no sólo las asociaciones de telespectadores constituidas como tales, sino la labor de otros muchos grupos que apoyan este movimiento, lo que deja ver la mutua cooperación que existe entre ellos y que ha dado como producto una extensa red de organismos que poco a poco van sumando fuerzas a nivel local y global, constituyéndose como grupos organizados que pueden llegar a ser 'representativos' por el número de personas que lo integran. Esto se ha logrado gracias a la suma del esfuerzo de cada uno de los organismos y asociaciones que muchas veces participan en las acciones relacionadas con la protección de los derechos de los niños y jóvenes, y a favor de la mejora de los contenidos de la televisión, principalmente. Todo ello es agregado en la tarea de ser tomados en consideración por los poderes gubernamentales al momento de hablar de la "representatividad".

Tal como expresa Boza Osuna (2005: 114): "el ser aglutinantes de otros movimientos y colectivos e integrarse a ellos en lugar de competir, es una tarea que reforzará las líneas de actuación de estas asociaciones y las hará cada vez más fuertes". También es importante señalar su afán por mantener vínculos con las asociaciones europeas de la misma índole y trabajar con ellas para la conformación de una asociación europea, inquietud que ha dejado ver el presidente de 'AC Media' (Asociación Portuguesa de Consumidores de los Media) Nuno Von Amann (De CAmpos Amann, 2005: 
Entrevista), quien ha reconocido su interés de que las asociaciones de telespectadores españolas tengan un referente internacional que las englobe y a la vez que las represente, dándole así, un mayor peso al movimiento asociativo de telespectadores.

Una de sus mayores fortalezas radica en la creación de "plataformas", donde la mayoría de estas asociaciones, aunado a la participación de muchas otras organizaciones de distinta índole que se suman a sus fines, apoyan este movimiento, lo que significa una forma de tener mayor representatividad y respaldo cara al Estado y a los intereses de los distintos agentes televisivos, por lo que se puede afirmar que mantienen un soporte de redes de solidaridad importante.

En referencia a esta idea, cabe remarcar que los sujetos aislados difícilmente pueden lograr transformaciones, pudiendo llegar a ser estas asociaciones las portavoces de un discurso único, que sólo podría adquirir más fuerza y provocar cambios contundentes en la programación televisiva, a través del apoyo de la participación ciudadana.

\subsection{Oportunidades}

\subsubsection{Contexto político, social y legislativo}

Es necesario destacar el posible campo de acción que se ha abierto para estos grupos en relación al contexto político presente, ya que el gobierno en turno ha significado un avance para la consecución de uno de sus objetivos más importantes: ganar terreno dentro de las políticas televisivas. Muestra de ello se refleja en su representación en los órgano de gobierno, como lo es el haber sido considerados para formar parte en la "Comisión Mixta de seguimiento" del "Código de autorregulación para los contenidos televisivos e infancia", así como en la "Comisión de seguimiento del Código Deontológico de la Publicidad Infantil". La coyuntura de este momento impulsó también la idea, desde hace algunos años atrás exigida en reiteradas ocasiones por las asociaciones, de poner en marcha la creación de un "Consejo Estatal para los Medios Audiovisuales", dejando entreabierta otra puerta que podría significar su probable inclusión.

La situación por la que atraviesa el sector televisivo, especialmente el área de los contenidos, podría considerarse una oportunidad para el desarrollo de las asociaciones de telespectadores, ya que desde hace algunos años, se viene poniendo énfasis en su regulación y tomando medidas que cada vez parecen más urgentes en este terreno. Asimismo, la Ley General de Comunicación Audiovisual pone en relieve la importancia de la promoción de la "alfabetización audiovisual", tarea en la que a partir de ahora se responsabilizará el Consejo Estatal de Medios Audiovisuales (CEMA), quien será el encargado de velar por el cumplimiento de este objetivo. Las asociaciones de telespectadores y otros grupos sociales deben aprovechar esta coyuntura legislativa para seguir actuando en colaboración con el Estado, tal y como lo han venido haciendo hasta ahora, en la organización de jornadas, cursos y charlas sobre temas de interés, en la búsqueda de una mayor "visibilidad" "17, cara a la ciudadanía.

${ }^{17}$ Una investigación realizada en algunas provincias españolas reveló que sólo un $11 \%$ de los encuestados afirmaba conocer alguna asociación de telespectadores; sin embargo el 88\% consideró que estas asociaciones podían llegar a desempeñar una función importante respecto a la televisión (RosiQue, 2007). 
Estos hechos están significando un resurgimiento de las asociaciones, lo que lleva a hacer un balance prospectivo positivo donde se puede vislumbrar su continuidad, su crecimiento y su proyección a futuro en el ámbito televisivo, con una mayor participación y peso en relación al resto de los agentes televisivos.

En síntesis, el panorama que se ha abierto en los últimos años respecto a las temáticas televisivas las ha puesto en el punto de mira, lo que ha multiplicado las alian-

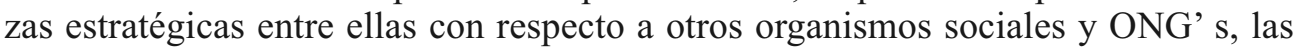
cuales seguirán siendo oportunidades de crecimiento y consolidación para el movimiento asociativo de telespectadores como parte de un plan estratégico de desarrollo, así como todos aquellos organismos a nivel internacional con los cuales mantienen vínculos y alianzas. De ello se desprende que vaya en aumento el número de organismos y asociaciones que se implican en las tareas realizadas por las asociaciones de telespectadores, tales como manifiestos y declaraciones. "Si hay un ámbito de actuación en el que este tipo de organizaciones parecen especialmente aptas para desenvolverse, dicho ámbito es precisamente el de la educación y promoción de los derechos y libertades" (Fuente CoBo, 2010: 113).

\section{Conclusiones}

Las asociaciones de telespectadores están produciendo una paulatina transformación en los tradicionales agentes televisivos: Estado y empresas audiovisuales, en relación al modelo unidireccional de funcionamiento del sector audiovisual. Esto obedece a una lógica de la naturaleza del desarrollo del medio y de la sociedad mediática en su conjunto. La primera fase se basó en la creación del capital físico, donde la importancia de esa etapa se basó en el diseño y el desarrollo de la infraestructura, donde el envío de la señal y la implantación de receptores fueron los pilares básicos para el surgimiento de un nuevo mercado; en ese momento el Estado fue su principal impulsor.

A su vez, el capital humano se forjaba en un entorno donde prevalecía el desconocimiento sobre este nuevo sistema de transmisión de imágenes, pero también como respuesta a la necesidad de ponerlo en funcionamiento; así, con el apoyo de ingenieros, técnicos y talentos provenientes de la radio, se puso en marcha la televisión.

Finalmente, la construcción del capital social se fue desarrollando, encontrándose actualmente en su nivel más alto, teniendo como primer ejemplo el surgimiento de iniciativas ciudadanas organizadas.

Este sistema de equilibrios entre los agentes televisivos es, como diría Hegel, el que corresponde mejor al "espíritu de los tiempos", en donde la sociedad civil está mejor protegida por las instituciones democráticas (Hegel, en BoBBio, 2004: 157). Sin embargo, no cabe duda que a diferencia del anterior escenario analógico, hoy en día las asociaciones de telespectadores se enfrentan a una mayor complejidad de retos que les exige una delimitación de sus objetivos para vislumbrar cuál es su función social en este nuevo panorama mediático y el alcance que con sus acciones pueden llegar a tener. Concretamente las Asociaciones de Telespectadores (ATR's) tendrán que evolucionar hacia el terreno de la convergencia de los medios tradicionales con las nuevas tecnologías, adaptándose a los nuevos hábitos, necesidades y preferencias de los telespectadores. 
En este sentido, cabe destacar la labor de la Asociación de Usuarios de la Comunicación (AUC) que desde hace algunos años viene desempeñándose en la defensa de los derechos de los ciudadanos, considerando entre sus líneas de acción los diferentes medios, soportes y sistemas de comunicación: publicidad, televisión, telefonía, nuevas tecnologías e Internet; este hecho y su vinculación al Consejo de Consumidores y Usuarios la han posicionado como la asociación más representativa en este sector cara al Estado.

Por otra parte, cabe destacar que tanto el Consejo Estatal de Medios Audiovisuales (CEMA) como los grupos organizados de esta índole, a partir de ahora deben caminar en paralelo en lo que se refiere a la canalización y/o generación de quejas y reclamaciones, con el fin de divulgar estas prácticas entre los usuarios de los medios y de no obstaculizar estos procesos una vez que se cuenten con procedimientos transparentes y eficaces para tramitar y dar respuesta a sus peticiones (FUENTE COBO, 2010). Asimismo, la labor que vienen realizando sobre la línea de promoción de la "alfabetización audiovisual" toma especial relevancia y continúa vigente a razón de la falta de una regulación eficaz en materia de contenidos; este hecho invita a que las asociaciones de telespectadores continúen trabajando en este ámbito de actuación.

Para llevar a cabo tareas de "alfabetización audiovisual", el Consejo Estatal de Medios Audiovisuales (CEMA) será el encargado de velar por el cumplimiento de este objetivo. Las asociaciones de telespectadores y otros grupos sociales deben aprovechar esta coyuntura legislativa para seguir actuando en colaboración con el Estado, tal y como lo han venido haciendo hasta ahora a través de la realización de actividades conjuntas.

Esta visibilidad es indispensable para que, muy concretamente las asociaciones de telespectadores (ATR's), puedan llegar a ser consideradas en el Comité Consultivo del Consejo Estatal de Medios Audiovisuales (CEMA), lo que constituiría un gran avance en la historia de estas asociaciones ya que sería la primera vez que lograrían ser partícipes en un órgano con potestad decisoria, lo cual significaría que podrían convertirse en verdaderos actores sociales, influyentes en la política de los medios de comunicación.

\section{Referencias bibliográficas}

ABRUZZESE, Alberto y MICONI, Andrea (1999): Zapping: sociología de la experiencia televisiva. Madrid, Cátedra.

AGRUPACIÓN DE TELESPECTADORES Y RADIOYENTES (2010): "X Informe ATR-Villanueva", en Agrupación de Telespectadores y Radioyentes: http://www.atr.org.es/informes/10Informe_ATRVillanueva.pdf [fecha de consulta: 14 de marzo de 2011]

ARRIBAS, Amaia (2010): "El reto de Internet está en la visibilidad y en la credibilidad. Entrevista a José Luis Orihuela", en Razón y Palabra, n 54, Ciudad de México, Tecnológico de Monterrey.

ASOCIACIÓN DE USUARIOS DE LA COMUNICACIÓN (AUC) (2009): “La participación del público en los espacios televisivos", en Asociación de Usuarios de 
la Comunicación: http://www.auc.es/Documentos/Notas\%20AUC/Notas2009/ Notas $\% 20$ AUC\%20\%20La\%20participacion $\% 20$ del $\% 20$ publico $\% 20$ en $\% 201$ os $\% 2$ 0espacios\%20televisivos.pdf [fecha de consulta: 12 de junio de 2009]

ASOCIACIÓN DE USUARIOS DE LA COMUNICACIÓN (AUC) (2010): "Evolución de la audiencia televisiva: mayo de 2010", en Asociación de Usuarios de la Comunicación: http://www.auc.es/Documentos/Notas\%20AUC/Notas2010/2010\%20Junio $\% 20 \% 20$ AUC $\% 20$ Notas $\% 20 \% 20$ Evolucion $\% 20$ de $\% 201 \mathrm{a} \% 20$ audiencia $\% 20$ televisiva\%20Mayo\%202010.pdf [fecha de consulta: 20 de diciembre de 2010]

BOBBIO, Norberto (2004): La teoría de las formas de gobierno en la historia de pensamiento político. Ciudad de México, Fondo de Cultura Económica.

BOURDIEU, Pierre (1974): Campo del poder y campo intelectual. Buenos Aires, Folios.

BOZA OSUNA, José (2005): "Las asociaciones de telespectadores en la construcción de una televisión de calidad", en Comunicar, n 25, Huelva, Grupo Comunicar, pp. 109-115.

CAFFAREL SERRA, Carmen (2007): “Algunas reflexiones en torno a la Televisión Digital Terrestre", en Icono 14, n. 9, Marid, Icono 14 Asociación Científica, pp. $1-21$.

CEBRIÁN, Mariano (2009): "Nuevas formas de comunicación: cibermedios y medios móviles", en Comunicar, n 33, Huelva, Grupo Comunicar, pp. 10-13.

CIS. Centro de Investigaciones Sociológicas (2010): "Barómetro Mayo de 2010", en: http://www.cis.es/cis/opencms/Archivos/Marginales/2820_2839/2836/es2836.pdf [fecha de consulta: 25 de agosto de 2010]

DE CAMPOS AMANN, Von Nuno (2005): Entrevista, Huelva a 25 de noviembre de 2005.

FERNÁNDEZ SANTILLÁN, José (2005): Sociedad civil: cultura politica y cultura ciudadana, Ciudad de México, Concepción Haydee Rojas Barradas.

FUENTE COBO, Carmen (1989): "Las obligaciones culturales de los servicios nacionales de televisión", en Telos. Cuadernos de comunicación, tecnología y sociedad, $\mathrm{n}^{\circ}$ 18, Madrid, Fundación Telefónica, pp. 34-41.

FUENTE COBO, Carmen (2010): “Ciudadanía activa y alfabetización mediática. El papel de las asociaciones de telespectadores y usuarios de los medios en el nuevo escenario audiovisual", en Icono 14, $\mathrm{n}^{\circ}$ 16, Madrid, Icono 14 Asociación Científica, pp. 102-117.

GARCÍA GARCÍA, Francisco y GERTRÚDIX, Manuel (2009): "El Mare Nostrum Digital: Mito, ideología y realidad de un imaginario sociotécnico", en Icono 14, $\mathrm{n}^{\circ}$ 12, Madrid, Icono 14 Asociación Científica, pp.7-30.

GARCÍA MATILLA, Agustín (2006): "El multimedia interactivo: reflexiones entorno a una revolución pendiente", en Cuadernos de Documentación Multimedia: http://www.ucm.es/info/multidoc/multidoc/revista/cuad6-7/agmatill.htm [fecha de consulta: 29 de agostode 2010] 
NAVARRO, Clemente J. y JUARISTI LARRINAGA, Patxi (2006): "Funciones, actividades y facilitación pública de las asociaciones", en MONTERO, J. R y TORCAL, M: Ciudadanos, asociaciones y participación en España. Madrid, Centro de Investigaciones Sociológicas, pp. 223-240.

OROZCO, Guillermo (1996): Televisión y audiencias. Un enfoque cualitativo. Madrid, La Torre.

PÉREZ TORNERO, José Manuel (2010): "Promover la alfabetización mediática es ya una obligación legal en España para los poderes públicos y los medios audiovisuales", en Pensamiento crítico y comunicación: http://jmtornero.wordpress.com/ tag/afabetizacion-mediatica/ [fecha de consulta: 14 de julio de 2010]

QUIRÓZ, María Teresa (1993): Todas las voces. Comunicación y educación en el Perú. Lima, Universidad de Lima.

ROSIQUE CEDILLO, Gloria (2007): "Nuevos actores sociales en el escenario audiovisual: las asociaciones de telespectadores"en Icono 14, n 9, Madrid, Icono 14 Asociación Científica, pp. 1-21.

TOFFLER, Alvin (1988): La tercera ola. Barcelona, Plaza y Janes.

USIETO, Ana (2010): "Lipdub, los vídeos musicales caseros", en El Heraldo: http://www.heraldo.es/noticias/detalle/lipdub los_videos_musicales_caseros.html [fecha de consulta: 8 de julio de 2010]

VARELA, Juan (2006): “La televisión participativa crece", en Periodistas: http://periodistas21.blogspot.com/2006/04/la-televisin-participativa-crece.html [fecha de consulta: 21 de abril de 2010] 